\title{
EDUCAÇÃO INCLUSIVA E A VALIDAÇÃO DO DIPLOMA ESCOLAR ESTRANGEIRO SOB A ÓTICA DA NOVA LEI DA MIGRAÇÃO No 13.445/2017
}

\author{
Juliana Tomiko Ribeiro Aizawa iD 1
}

\section{Resumo}

A temática voltada as migrações tem chamado atenção de estudiosos e despertado certo interesse social, em razão da edição da Nova Lei das Migrações no 13.445/2017 e o número expressivo de mais de 79,5 milhões deslocados pelo mundo (ACNUR, 2020). O trabalho objetiva analisar os mecanismos que viabilizam a validação do diploma escolar estrangeiro no Brasil, a fim de integrar os(as) migrantes a nova sociedade ingressa e propiciar melhores condições laborais. Para desenvolver o estudo foi adotada como metodologia a pesquisa bibliográfica; qualitativa; básica, de cunho exploratório, através da legislação nacional e internacional consultada em sites oficiais como: ONU, UNESCO, Planalto; os marcos teóricos são: Dalmo de Abreu Dallari, Fábio Konder Comparato, Peter Mittler, Zygmund Bauman. O enfoque é a educação inclusiva escolar para migrantes no estado de Mato Grosso do Sul, através de uma perspectiva analítica entre o Direito, Relações Internacionais e Educação, com recorte temporal entre a promulgação da Constituição Federal de 1988 e a última consulta realizada na plataforma digital da Secretaria de Educação (SEC) do respectivo estado federado. Como premissa geral do estudo realizado foi diagnosticado que embora haja esforços internacionais e normas constitucionais fundamentais, tornar oportuna e acessível a educação inclusiva ainda carece de fronteiras a serem ultrapassadas, mais precisamente a viabilidade de informações quanto aos procedimentos administrativos e judiciais.

Palavras-chave: Direitos Humanos; Direito a Educação; Educação Inclusiva; Migração; Nova Lei da Migração.

\section{INCUSIVE EDUCATION AND THE VALIDATION OF THE FOREIGN SCHOOL DIPLOMA UNDER THE VIEW OF THE NEW MIGRATION LAW No 13.445 / 2017}

\section{Abstract}

The thematic of migration has drawn the attention of academics and aroused a certain social interest, due to the edition of the New Law on Migration $n^{\circ} .13,445$ / 2017 and the expressive number of more than 79.5 million displaced around the world (UNHCR, 2020). The paper objective to analyze the mechanisms that make possible the validation of the foreign qualification certificate in Brazil, in order to integrate migrants, the new society enters and provide better working conditions. To

\footnotetext{
${ }^{1}$ Mestre em Fronteiras e Direitos Humanos pela Universidade Federal da Grande Dourados (UFGD). Graduada em Direito pela Universidade Federal de Mato Grosso do Sul (UFMS/CPTL). Atualmente é professora de direito e prática processual civil no Centro Universitário da Grande Dourados (UNIGRAN). Orientadora no Núcleo de Prática e Assistência Jurídica do NPAJ UNIGRAN Dourados (MS). Coordenadora do Grupo de Pesquisa Mobilidade Integração e Direitos Humanos da UNIGRAN Dourados (MS). Professora Associada à Academia Brasileira de Direito Internacional (ABDI). Advogada com ênfase em Direito Público.
} 
develop the study, bibliographic research was adopted as a methodology; qualitative; basic, exploratory, through national and international legislation consulted on official websites such as: UN, UNESCO, Planalto; the theorists are: Dalmo de Abreu Dallari, Fábio Konder Comparato, Peter Mittler and Zygmund Bauman. The focus is on inclusive school education for migrants in the state of Mato Grosso do Sul, through an analytical perspective between Law, International Relations and Education, with a time frame between the promulgation of the 1988 Federal Constitution and the last consultation held on the digital platform of the Secretariat of Education (SEC) of the respective federated state. As a general premise of the study carried out, it was diagnosed that although there are international efforts and fundamental constitutional norms, making inclusive education timely and accessible still lacks obstacle to be crossed, more precisely the feasibility of information regarding administrative and judicial procedures.

Keywords: Human Rights; Right to Education; Inclusive Education; Migration; New Law for Migration.

\section{Introdução}

A temática voltada as migrações tem chamado atenção de estudiosos e despertado certo interesse social, em razão da edição da Nova Lei das Migrações no $13.445 / 2017$ e o número expressivo de mais de 79,5 milhões deslocados pelo mundo (ACNUR, 2020).

Assim sendo, através de uma perspectiva analítica entre o Direito, Relações Internacionais e Educação, este artigo propõe suprir uma lacuna identificada sobre o tema, qual seja, mecanismos de integração social dos migrantes a nova sociedade ingressa, em especial a validação do diploma escolar estrangeiro.

Isso porquê a mão de obra migrante é marca perene nos registros históricos nacionais, a princípio em trabalhos operacionais. Muito embora esses migrantes já possam ter cumulado experiências laborais de onde vieram e desenvolver ofícios com grande habilidade, porém as restrições burocráticas para reconhecer tais especialidades são diversas e com informações desacertadas ou de difícil compreensão.

Tais aspectos foram observados com as novas ondas migratórias, de forma mais expressiva a partir do ano de 2010 através da migração haitiana para o Brasil, que ao longo desses 10 anos de migração (2010-2020), as diversas barreiras integrativas superadas já foram superadas, como: acolhida, documentação, residência, idioma e trabalho. Viabilizar, portanto, o acesso à educação é uma ferramenta integrativa impreterível, que propicia novas oportunidades a população migrante.

Vislumbrando tal problemática o objetivo desse artigo é apresentar mecanismos que possibilitam a validação do diploma escolar estrangeiro no Brasil, especialmente no estado federado de Mato Grosso do Sul, aonde foi desenvolvida a pesquisa.

Deste modo, inicialmente discorremos sobre a consciência humanitária do direito, assumida no pós-segunda guerra mundial, a ratificação da Declaração Universal dos Direitos Humanos (DUDH) de 1948 e o enrijecimento de normas constitucionais fundamentais, a fim de garantir direitos básicos a cada indivíduo. 
Ainda que, não seja o direito expresso na DUDH o acesso à educação como pauta no direito internacional teve especial atenção após os anos de 1990, com os Fóruns Mundiais de Educação organizados pela Organização das Nações Unidas para a Educação, a Ciência e a Cultura (UNESCO).

Assim sendo, observou os impactos referentes à Declaração de Incheon de 2015 que foi o marco de ação firmado pelos Estados signatários a ser alcançado até 2030, cujo objetivo geral é oferecer educação de qualidade inclusiva e equitativa para todos, em todos os níveis (UNESCO, 2015).

A fim de viabilizar o acesso à educação a população migrante notou-se uma oportunidade em cumular os objetivos consignados na Declaração de Incheon com a política migratória brasileira ${ }^{1}$. Deste modo, a segunda seção atentou-se em trazer o novo significado de Estado nação, ante a porosidade das fronteiras perpassadas pela globalização e migração em massa.

Além disso, trouxe um especial enfoque no direito e acesso à educação inclusiva com a previsão do texto da Constituição Federal de 1988, o artigo 30 da Lei da Migração no 13.445/2017, Lei de Diretrizes e Bases da Educação no 9.394/1996 e a Declaração de Incheon de 2015.

Por fim, a terceira seção trata de modo objetivo os procedimentos para validar o diploma escolar estrangeiro. Explora os instrumentos administrativos a serem usados por analogia em situação de insuficiência de recursos, para desonerar as taxas e emolumentos. Apresenta os tradutores e interpretes de documentos do estado de Mato Grosso do Sul e em casos de insucesso no requerimento administrativo da isenção de custas, um possível mecanismo processual civil para requerer a reparação da lesão do direito líquido e certo

O enfoque é a educação inclusiva escolar para migrantes no estado de Mato Grosso do Sul, com recorte temporal entre a promulgação da Constituição Federal de 1988 à última consulta das informações administrativas constantes na Secretaria de Educação (SEC) em 2020. Diante desses breves aspectos introdutórios passaremos a análise da temática proposta.

\section{Subtítulo: referencial teórico}

Os marcos teóricos adotados são: Dalmo de Abreu Dallari, Fábio Konder Comparato, Peter Mittler e Zygmund Bauman.

\section{Metodologia}

Para desenvolver o estudo foi adotada como metodologia a pesquisa bibliográfica; qualitativa; básica, de cunho exploratório, através da legislação nacional e internacional consultada em sites oficiais como: Organização das Nações Unidas (ONU), UNESCO, Portal da Legislação brasileira - Planalto.

\section{Resultados e discussões}

\footnotetext{
${ }^{1}$ Política migratória é uma forma de regulamentar o fluxo de pessoas que podem ou não entrar no território brasileiro (TARGIONI, 2017).
} 
No mundo contemporâneo não há como falar sobre educação inclusiva sem antes descrever, ainda que brevemente, os precedentes acerca da internacionalização dos Direitos Humanos. A Declaração Universal dos Direitos Humanos (DUDH) de 1948, elaborada pela Organização das Nações Unidas (ONU) é um instrumento jurídico internacional, escrito, que objetiva garantir direitos basilares que possam propiciar manutenção da vida humana.

Isso porque o signo do pós-segunda guerra mundial, consolidou-se na história como "a ruptura do paradigma dos direitos humanos, por meio da negação do valor da pessoa humana como valor-fonte do Direito" (PIOVESAN, 2012, p. 37). O poder autoritário, fruto de um regime ditador firmado por um discurso de sobreposição de "raças", sendo, na realidade há uma única espécie - humana; forçou no pós guerra a formação de constituições rígidas, que assegurassem direitos fundamentais, a fim de evitar o retrocesso legal.

Ainda que, os direitos humanos sejam assimilados como direitos fundamentais, insta distinguir a similitude de ambos. Os direitos humanos têm um caráter universal e objetiva alcançar a todos os povos, enquanto os direitos fundamentais são aqueles previstos e assegurados, principalmente em constituições "Modernas" que convalidam a norma de caráter universal (COMPARATO, 1997, p.192).

O intuito de ter normas jurídicas positivadas de direitos humanos por intermédio de Cartas Constitucionais Modernas é limitar "qualquer espécie de poder absoluto e antidemocrático, poder que se pretenda exercer arbitrariamente em prejuízo da pessoa humana, de sua dignidade e de seus direitos fundamentais" (DALLARI, 2010, p. 348).

O enrijecimento, previsão e validação de normas constitucionais fundamentais são impreteríveis ante a hegemonia da economia mundial. No mercado global e na "livre" concorrência, não há pacto de estabilidade entre países e nem crescimento econômico que escape à lógica da captação de investimentos internacionais.

Isso porquê a globalização fomentou a mobilidade da própria sociedade, "quando na história começaram a ocorrer choques e interação de diferentes culturas, que passaram a trocar e assimilar informação, conhecimento científico, técnicas e culturas" (MENEZES, 2013, p.87), aparecendo timidamente em meados do século XX e intensificando-se no início do século XXI.

O impacto exercido por esse fenômeno, que tem em seu cerne a formação de um capital global, afeta de diferentes formas o mercado de trabalho, saúde, educação e qualidade de vida da população, a depender da região global em que intensifica estes acordos comerciais internacionais.

[...] para a massa da população, já assombrada pela fragilidade existencial e pela precariedade de sua condição e de suas expectativas sociais, esse influxo sinaliza ainda mais competição pelo mercado de trabalho, uma incerteza mais profunda e chances declinantes de melhoramento: um estado mental politicamente explosivo- com políticos oscilando com dificuldade entre os desejos incompatíveis de satisfazer seus amos detentores de capital e aplacar o medo dos eleitores (BAUMAN, 2017, p. 10).

Em razão desta discrepância político-econômica mundial, a consignação de direitos sociais em cartas constitucionais pelos Estados, alicerçam expectativas e não garantias. As políticas públicas optam por encaminhar os direitos públicos para grandes investimentos infra estruturantes (aeroportos, vias férreas, autoestradas), 
em vez de os onerar para os serviços garantidores na esfera social (CANOTILHO, 1997, p.22).

Um destes serviços garantidores é o acesso à educação. Atualmente, não há nenhuma carta constitucional que desconheça, ou não tenha garantido o direito a educação. Sabe-se que este não é um direito posto, emergido do estado de natureza há época listados nas doutrinas jusnaturalistas - direito natural "tido como direito comum" (CARVALHO, 2015, p.53), mas um direito elementar para a sociedade.

A verdade é que esse direito não fora posto no estado de natureza porque não emergira na sociedade da época em que nasceram as doutrinas jusnaturalistas, quando as exigências fundamentais que partiam daquelas sociedades para chegarem aos poderosos da Terra eram principalmente exigências de liberdade em face das Igrejas e dos Estados, e não ainda de outros bens, como o da instrução, que somente uma sociedade mais evoluída econômica e socialmente poderia expressar (BOBBIO, 2004, pp. 69/70).

Em tempos pretéritos a educação era um direito garantido às sociedades mais evoluídas economicamente, o que não deriva, na atualidade, da realidade das ex colônias dos países "socialmente mais expressivos" cognitivamente (BOBBIO, 2004). Os problemas enfrentados pela humanidade na sistemática da globalização, principalmente em países nominados como subdesenvolvidos, emergem da fome à falta de água potável, destruição de recursos naturais, dívida internacional interminável, o abismo e alienação digital, do analfabetismo e ausência de políticas públicas inclusivas.

A educação como direito passou a ser pautada internacionalmente a partir da Conferência Mundial sobre Educação para todos, que aconteceu em Jomtien, na Tailândia, em 1990. Nesta oportunidade, foi elaborada a Declaração Mundial sobre Educação para Todos: Satisfação das Necessidades Básicas de Aprendizagem, o documento reafirma o direito a educação e as medidas para que todos possam acessá-Io (UNESCO, 1990).

Embora desde 1948 a questão da educação como direito de todos esteja posta na Declaração Universal dos Direitos Humanos, foi no final do século XX que a UNESCO (Organização das Nações Unidas para a Educação, a Ciência e a Cidadania) decidiu colocar como sua prioridade número um as discussões sobre a necessidade de universalização da educação básica (DESLANDES; LOURENÇO, 2011, p.39).

Passa-se a remontar a necessidade de priorizar mecanismos universais, em que a educação básica seja dotada como condição basilar no desenvolvimento humano. Para tanto, universalizar o acesso à educação como forma de promover a equidade, os Estados signatários devem assumir o compromisso efetivo em superar as disparidades, principalmente no que tange ao acesso às oportunidades educacionais dos grupos excluídos: minorias étnicas, raciais e linguísticas (UNESCO, 1990).

Notando o envolvimento crescente dos governos, em busca da promoção ao acesso à educação para a maioria das pessoas com necessidades especiais, as autoridades governamentais juntamente com agências especializadas participaram da Conferência Mundial sobre Necessidades Educativas Especiais em Salamanca na 
Espanha, firmando a Declaração de Salamanca sobre Princípios, Política e Práticas na Área das Necessidades Educativas Especiais em 1994 (UNESCO, 1994).

Em 2000 o Fórum Mundial de Educação foi em Dacar, capital do Senegal localizado na África Ocidental. O evento reafirmou as pretensões, compromissos das convenções anteriores e consignou que "a educação é um direito humano fundamental e [...] meio indispensável para alcançar a participação efetiva nas sociedades e economias do século XXI afetadas pela rápida globalização" (UNESCO, 2000, p. 8).

O último Fórum Mundial de Educação ocorreu em 2015, na cidade de Incheon, Coreia do Sul. A Declaração de Incheon teve por meta correspondente: Assegurar a educação inclusiva e equitativa de qualidade, e promover oportunidades de aprendizagem ao longo da vida para todos. O evento teve como coorganizadores o Banco Mundial, Programa das Nações Unidas para o Desenvolvimento (PNUD), Fundo das Nações Unidas para a Infância (UNICEF), ONU Mulheres e Alto Comissariado das Nações Unidas para Refugiados -ACNUR (UNESCO, 2015).

O objetivo da inclusão está atualmente no coração da política educacional e da política social (MITTLER, 2007, p. 24). Isso porque a educação, recentemente adotou a semântica - inclusiva, como elemento chave para atingir pleno emprego e erradicação da pobreza (UNESCO, 2015). Esta movimentação visa aumentar a participação, aprendizado e reduzir por meio da educação a exclusão de crianças, jovens e adultos.

Apesar de serem usadas como sinônimos: integração e inclusão, há diferenças substanciais práticas entre os dois termos na educação. A integração visa melhores práticas metodológicas, por intermédio dos professores e equipamentos especiais nas escolas para o sistema regular de ensino. Já a inclusão é uma sistemática que celebra a diversidade, para que os alunos se sintam acolhidos em âmbito educacional, independente do gênero, nacionalidade, língua materna, deficiência e situação social (MITTLER, 2007, p.34).

A educação inclusiva por ter uma sistemática mais abrangentes e acolhedora, abarca, também, o acesso a tal direito por migrantes e refugiados. Aspecto a ser notado, principalmente, quanto a especial participação do ACNUR (Alto Comissariado das Nações Unidas para Refugiados) como coorganizador na Declaração de Incheon 2015.

A ONU em parceria com o ACNUR e a OIM (Organização Internacional das Migrações) vem sinalizando mecanismos com o intuito de auxiliar a política migratória para integração dos migrantes e refugiados no território de acolhimento. Por intermédio de instrumentos internacionais, em que os Estados contratantes, por exemplo, firmem o compromisso em buscar uma educação inclusiva e equitativa de qualidade como forma de expandir o alcance dos direitos humanos, via norma de caráter fundamental.

Acerca do assunto, na seção seguinte passaremos a abordar a política migratória brasileira e a educação inclusiva como mecanismo de integração dos migrantes no Brasil. 


\section{Política migratória brasileira e a educação inclusiva sob a ótica da Lei no $13.445 / 2017$}

As interações contemporâneas de Estados submetidos a hegemonia de uma economia global, tendem a aproximar o desenlace voltado a recepção de migrantes em seu território "soberano". A soberania do Estado-nação foi enfraquecida, pois os problemas a serem tratados não são tão somente os domésticos. "Todas as unidades estão fadadas a buscar soluções locais para problemas globalmente engendrados" (BAUMAN; BORDONI, 2017, p.34).

O que chama a atenção, contudo, é o fato de a questão migratória ser observada pela ótica do Estado-nação, em abordagens tipicamente realistas do sistema internacional, em que o indivíduo - o ser humano - migrante não é tomado como agente ou como sujeito de direitos, mas como um elemento da equação de fluxos migratórios, que gera efeitos para o Estado emissor e para o receptor (SICILIANO, 2013, p.11).

Estes reflexos globais que, também, eclodiram no Brasil mais incisivamente em 2010, após o terremoto que assolou o Haiti impulsionando o crescente fluxo migratório do Caribe para a América Latina. Trouxe para a ótica local (nacional), uma realidade internacional.

Válido relembrar que, ao longo da história brasileira os pilares laborais agroexportadores foram sustentados, a priori, pela mão de obra escrava, que foi substituída após os anos de 1900, com a abolição da escravatura, por migrantes japoneses, alemães e italianos (CARDOSO, 1998, p.40).

A política migratória era estabelecida por relações consulares entre os países cedentes da mão de obra migrante e Brasil. No entanto, tão somente no regime militar houve a formalização do Estatuto do Estrangeiro, por meio da Lei no 6.815/1980. Este dispositivo legal teve por intuito restringir a entrada dos estrangeiros no país, com um viés totalmente securitário.

Além disso, o interesse pelo estrangeiro a partir de 1980, era propiciar mãode-obra especializada aos vários setores da economia nacional e captar recursos para setores específicos. Desta forma, o Conselho Nacional de Imigração (CNIg) foi instituído como órgão de deliberação coletiva, integrando o Ministério do Trabalho ${ }^{1}$, via Decreto no 840, de 22 de junho de 1993 (BRASIL, 1993).

As deliberações do CNIg são feitas por meio de resoluções, o qual tem por atribuição: formular a política de imigração, coordenar e orientar as atividades de imigração, efetuar o levantamento periódico das necessidades de mão-de-obra estrangeira qualificada para admissão em caráter permanente ou temporário (BRASIL, 1993).

Até então a política nacional de imigração era tratada como um assunto de "polícia" - Ministério da Justiça, pela delimitação legal do Estatuto do Estrangeiro. E objetivava a imigração econômica, pois era gerida pelo Ministério do Trabalho e Emprego, em uma seção designada ao CNIg com a titulação "Política Nacional de Imigração e Proteção ao Trabalhador Migrante".

\footnotetext{
${ }^{1}$ A Medida Provisória no 870, de $1^{\circ}$ de janeiro de 2019, criou o Ministério da Economia. Com isso, as estruturas dos ministérios da Fazenda; do Planejamento, Desenvolvimento e Gestão; da Indústria, Comércio Exterior e Serviços; e do Trabalho passaram a integrar um novo ministério chamado Economia (BRASIL, 2019).
} 
Nota-se que a política migratória brasileira previa a permanência do estrangeiro, resguardados: os interesses nacionais, precipuamente à segurança nacional, interesses políticos, socioeconômicos e trabalho imigrante (BRASIL, 1980). Com a mudança de perspectiva global, o tratamento do migrante incidiu em alterações da legislação interna, voltando o olhar do legislador para uma realidade que vai além de questões meramente controladoras, policiais e estatais (MARINUCCI; MILESI, 2005).

Ante a esta necessidade, recentemente o Estatuto do Estrangeiro foi revogado, em razão da promulgação da Lei da Migração no 13.445, de 24 de maio de 2017. Este dispositivo foi instituído de forma harmoniosa com a previsão do texto da Constituição Federal de 1988, como principal mudança de paradigma da segurança nacional para a proteção dos direitos humanos (BASTOS, 2014, p.114).

O CNIg continua a operar, deliberando em consonância com a Lei da Migração, editando novas resoluções. Ainda que, a Lei no 13.445/2017 tenha sido aprovada com mais de 30 (trinta) vetos presidenciais (BRASIL, 2017 b), é vista como um grande avanço para a política migratória nacional (OLIVEIRA, 2017). Pois, formalizou o acolhimento humanitário (visto humanitário), reunião familiar, acesso a serviços sociais, inclusão laboral e o reconhecimento de formação acadêmica obtida no exterior (BRASIL, 2017).

Nesta oportunidade, daremos especial enfoque a formação acadêmica obtida no exterior, como política social de educação inclusiva ao migrante internacional. No capítulo anterior, destacou-se que a educação inclusiva foi pautada na Declaração de Incheon 2015. Na ocasião estavam presentes: o ministro da Educação do Brasil Renato Janine Ribeiro; a representante da UNESCO no Brasil - Lucien Muñoz; e a coordenadora de Educação da UNESCO no Brasil - Rebeca Otero (ONUBR, 2015).

O Brasil não só participou do evento organizado pela UNESCO, como se comprometeu com a visibilidade, fundamentação e princípios do marco de ação da Declaração de Incheon. Entre eles, destacamos:

\begin{abstract}
10. A educação como um direito humano fundamental e um direito catalisador. Para realizar esse direito, os países precisam garantir acesso universal igualitário a educação e aprendizagem de qualidade inclusiva e equitativa, que deve ser gratuita e compulsória e não deve deixar ninguém de fora. A educação deverá visar ao desenvolvimento completo da personalidade humana, assim como promover a compreensão mútua, a tolerância, a amizade e a paz (UNESCO, 2015, p. 8).
\end{abstract}

O acesso universal igualitário a educação inclusiva, como um direito humano fundamental para o desenvolvimento da personalidade, tolerância, compreensão mútua, tolerância e paz já estava previsto no rol - da ordem social da Constituição Federal de 1988.

Art. 205. A educação, direito de todos e dever do Estado e da família, será promovida e incentivada com a colaboração da sociedade, visando ao pleno desenvolvimento da pessoa, seu preparo para o exercício da cidadania e sua qualificação para o trabalho.

Art. 206. O ensino será ministrado com base nos seguintes princípios:

I - igualdade de condições para o acesso e permanência na escola (BRASIL, 1988). 
Previsão Constitucional foi reafirmada pela Lei de Diretrizes e Bases da Educação no 9.394, de 20 de dezembro de 1996. Em que o artigo 2 prevê que a educação é dever do Estado, inspirado nos princípios de liberdades e nos ideais de solidariedade humana, cuja finalidade é o pleno desenvolvimento do educando, seu preparo para o exercício da cidadania e qualificação para o trabalho. Concomitante a isso, o artigo 3 prevê que o ensino será ministrado segundo o princípio da igualdade para o acesso e permanência na escola (BRASIL, 1996).

A Lei da Migração em seu artigo $3^{0}$ traz um rol de princípios que passam a reger a nova política migratória, entre eles o inciso décimo primeiro prevê o acesso igualitário e livre do migrante a educação (BRASIL, 2017). A garantia dos princípios é impreterível, principalmente no que concerne inclusão social do migrante e sua integração ao mercado de trabalho.

A educação inclusiva destaca-se por desenvolver mecanismos que abarcam a diversidade, de forma mais acolhedora. A nova onda migratória de massa, primeiramente a haitiana, recebida a partir de 2010, e mais recentemente venezuelana além da barreira linguística, apenas ativam-se em serviços operacionais em razão da dificuldade que encontram quanto a revalidação do diploma estrangeiro.

O que necessitamos, aqui no Brasil, é regularizar a documentação; para mim é difícil trabalhar na minha profissão por falta da legalização dos documentos. Espero poder trabalhar na minha profissão; prometeram-me ajuda neste sentido (Migrante Feminina. Manaus) (BRASÍLIA, 2014, p.29).

A legislação vigente, desde os compromissos internacionais, a disposições constitucionais e norma infralegal possibilitam a revalidação do diploma estrangeiro como um instrumento de educação inclusiva. A carência é quanto aos procedimentos administrativos, para tanto passaremos a explorar os mecanismos práticos aplicáveis a esse direito.

\section{Procedimentos para a revalidação do diploma escolar estrangeiro em Mato Grosso do Sul}

As revalidações dos diplomas de nível fundamental e médio são realizadas nas Secretarias Estaduais de Educação e não tramitam via processo administrativo perante o Ministério da Educação. Para o migrante que deseja reconhecer respectivo documento, o primeiro passo é validar o certificado via consulado e providenciar a tradução juramentada do histórico escolar e diploma (BRASIL, 2018).

No Estado de Mato Grosso do Sul, os Tradutores Públicos e Intérpretes estão designados no site da Junta Comercial (JUCEMS) ${ }^{1}$ e a Tabela de emolumentos profissionais devidos aos tradutores públicos e intérpretes foi fixada por meio da Deliberação/JUCEMS/ no 001/2009, de 30 de março de 2009.

\section{Art. $10 \ldots$}

\section{A- TEXTOS COMUNS:}

Passaportes, certidões de registros civis, carteiras de identidade, de habilitação profissional, certificados e diplomas escolares, documentos similares, inclusive cartas pessoas que não envolvam textos jurídicos, técnicos ou científicos:

\footnotetext{
${ }^{1}$ JUNTA COMERCIAL DO ESTADO DE MATO GROSSO DO SUL (JUCEMS) (Mato Grosso do Sul). Agentes Auxiliares
} - Tradutores. 2020. Disponível em: <https://bit.ly/33ZXW39 >. Acesso em: 03 mai. 2020. 
Após a tradução do documento, o interessado deverá fazer um requerimento junto a Secretaria de Educação (SED) do estado. Feita a solicitação e obtida a equivalência do diploma escolar, o migrante estará apto para utilizar o certificado de nível fundamental e médio (BRASIL, 2018).

No entanto, é de comum conhecimento as dificuldades financeiras enfrentadas pelos migrantes, principalmente para custear as altas taxas de emolumentos fixadas. Neste sentido, importante trazer ao conhecimento o teor da Portaria no 218, de 27 de fevereiro de 2018 do Ministério da Justiça e Segurança Pública que dispõe sobre o procedimento de avaliação da condição de hipossuficiência econômica para fins de isenção de taxas, obtenção de documentos de regularização migratória e de pagamento de multas.

A obtenção de tal benefício é combinado com os mecanismos da auto declaração, prevista na Lei no 7.115, de 29 de agosto de 1983. O declarante precisa demonstrar insuficiência de recursos e a renda familiar de até meio salário mínimo per capita ou renda familiar total de até 03 (três) salários mínimos (BRASIL, 2018).

$\mathrm{Na}$ hipótese de falsidade da declaração, o solicitante ficará sujeito ao pagamento de taxa ou multa correspondentes e às sanções administrativas, civis e penais aplicáveis (BRASIL, 2018). No entanto, se tal benesse não for aplicada por analogia a isenção de emolumentos para a tradução dos diplomas escolares, há a possibilidade do(a) interessado(a) ingressar na via judicial e requere-la.

Eis que, o Código de Processo Civil de 2015 dispõe a gratuidade de justiça a remuneração do interprete ou tradutor nomeado para apresentação de versão em português de documento redigito em língua estrangeira.

Art. 98. A pessoa natural ou jurídica, brasileira ou estrangeira, com insuficiência de recursos para pagar as custas, as despesas processuais e os honorários advocatícios tem direito à gratuidade da justiça, na forma da lei.

$\S 1$ 으 A gratuidade da justiça compreende:

$[\ldots]$

VI - os honorários do advogado e do perito e a remuneração do intérprete ou do tradutor nomeado para apresentação de versão em português de documento redigido em língua estrangeira (BRASIL, 2015).

Combinado com este dispositivo, a Lei da Migração prevê no artigo $4^{\circ}$, no inciso IX - "amplo acesso à justiça e à assistência jurídica integral gratuita aos que comprovarem insuficiência de recursos" (BRASIL, 2017). Restando comprovada as evidencias que garantam a concessão da Justiça Gratuita, o instrumento processual hábil para propor a demanda na via judicial é o Mandado de Segurança, pois a situação em análise comporta a violação de direito líquido e certo (art. $5^{\circ}$, inciso LXIX da CRFB/88) e preenchem os pressupostos da Lei do Mandado de Segurança no 12.016, de 07 de agosto de 2009.

Por fim, ressaltamos que o Mandado de Segurança por ser um remédio constitucional, pode ser processado sob os benefícios da justiça gratuita no momento de sua impetração. Além disso, aporta um caráter mais célere em que analisa o direito material, qual seja, prova documental acerca da violação de um direito líquido e certo. 


\section{Considerações finais}

No contexto das migrações contemporâneas e hegemonia do capital global, buscar mecanismos na orbita do Direito Internacional é indispensável, a fim de que todos os Estados visem efetivar normas de direitos humanos, com caráter fundamental. O direito a educação já era um compromisso consignado na Declaração Universal de Direitos Humanos de 1948.

Outrora, começou a ser pautado internacionalmente a partir de 1990, como marco inaugural a Declaração Mundial sobre Educação para todos, de Jomtien na Tailândia, em 1990. Os Fóruns Mundiais da Educação sucessivos reiteraram o compromisso da educação como um direito humano, em 2000 na cidade de Dacar Senegal, na África Ocidental; e em 2015 na cidade de Incheon, Coreia do Sul.

Houve especial enfoque à Declaração de Incheon de 2015, por ter convocado os países signatários a firmar compromisso internacional, como plano de ação: assegurar a educação inclusiva e equitativa de qualidade. Visto que, a educação inclusiva por ser mais abrangente propicia mecanismos eficazes para a integração dos migrantes ao mercado de trabalho.

A validação de diploma escolar estrangeiro é um exemplo que viabiliza o reconhecimento qualificado da mão de obra. No Brasil, por exemplo, o campo de trabalho sem o ensino básico é tão somente a oferta de trabalhos operacionais. Destaca-se que a política migratória avançou com a promulgação da Lei da Migração no $13.445 / 2017$, em dispor no artigo 30 um rol de princípios humanitários para a acolhida e assegurar direitos basilares aos migrantes.

O CNIg tem reformulado as resoluções para que operem harmonicamente com a Nova Lei da Migração, combinando mecanismos práticos para que os migrantes tenham acesso isonômico as políticas públicas migratórias. A lacuna identificada é que existem inúmeros direitos garantidos no novo dispositivo legal que carecem de amadurecimento prático.

A validação de diploma escolar estrangeiro é um exemplo perene, os migrantes buscam o reconhecimento deste documento, no entanto a operacionalização do direito ainda se encontra congestionada por desconhecimento das vias administrativas e procedimentais a serem buscadas.

Outro fator recorrente é a insuficiência de recursos financeiros para validar o diploma escolar estrangeiro, neste tocante, também foi apontada uma alternativa com base na interpretação do texto legal. Por fim, observa-se que o trabalho propõe aplicar as leis que já existem, não se tratando de um novo direito, mas um direito fundamental para o desenvolvimento harmônico, passivo, inclusivo na integração social do migrante ao novo Estado nacional em que passou a firmar domicílio.

Como premissa geral do estudo realizado foi diagnosticado que embora haja esforços internacionais e normas constitucionais fundamentais, tornar oportuna e acessível a educação inclusiva ainda carece de fronteiras a serem ultrapassadas, mais precisamente a viabilidade de informações quanto aos procedimentos administrativos e judiciais

\section{REFERÊNCIAS}

ACNUR, Alto Comissariado das Nações Unidas para Refugiados (ACNUR). Global Trends Forced Displacement in 2019. 2020. Dinamarca. Disponível em: https://bit.ly/37a8ZsA Acesso em: 08 de agos. 2020. 
BASTOS, Renata Parize. Globalização, migração e direito: regulação dos movimentos migratórios no Brasil. 2014. 409 f. Dissertação (Mestrado) - Curso de Direito Político e Econômico, Universidade Presbiteriana Mackenzie, São Paulo, 2015. Disponível em: https://bit.ly/31rltIX. Acesso em: 03 out. 2018.

BAUMAN, Zygmunt. Estranhos à nossa porta. Rio de Janeiro: Zahar, 2017. Tradução de: Carlos Alberto Medeiros.

BAUMAN, Zygmunt; BORDONI, Carlo. Estado de Crise. Rio de Janeiro: Zahar, 2016. Tradução: Renato Aguiar.

BOBBIO, Norberto. A era dos Direitos. Rio de Janeiro: Elsevier, 2004.

BRASIL. Lei nº 6.815, de 19 de agosto de 1980. Estatuto do Estrangeiro. Brasília, Disponível em: https://bit.ly/377nEon. Acesso em: 03 nov. 2018.

BRASIL. Constituição (1988). Constituição da República Federativa do Brasil, de 05 de outubro de 1998. Brasília, Disponível em: https://bit.ly/350LaAT. Acesso em: 03 nov. 2018.

BRASIL. Decreto no 840, de 22 de junho de 1993. Organização e o Funcionamento do Conselho Nacional de Imigração e Dá Outras Providências. Brasília, Disponível em:

https://bit.ly/3dvl3pJ. Acesso em: 03 nov. 2018.

BRASIL. Lei no 9394, de 20 de dezembro de 1996. Diretrizes e Bases da Educação Nacional. Brasília, Disponível em: https://bit.ly/3dGf4yt. Acesso em: 02 nov. 2018.

BRASIL. Lei no 12.016, de 07 de agosto de 2009. Disciplina 0 Mandado de Segurança

Individual e Coletivo e Dá Outras Providências. Brasília, Disponível em: https://bit.ly/3IKjgQc. Acesso em: 03 nov. 2018.

BRASIL. Deliberação/JUCEMS no 001, de 30 de março de 2009. Tabela de Emolumentos Profissionais Devidos Aos Tradutores Públicos e Intérpretes Comerciais do Estado de Mato Grosso do Sul. JUNTA COMERCIAL DO ESTADO DE MATO GROSSO DO SUL. Campo Grande, MS, Disponível em: https://bit.ly/31ajl8i. Acesso em: 03 nov. 2018.

BRASIL. Súmula no 481, de 28 de junho de 2012. Justiça Gratuita: STJ. Brasília, Disponível em: https://bit.ly/35gvgTh. Acesso em: 02 nov. 2018.

BRASIL. Lei n 13.105, de 16 de março de 2015. Código de Processo Civil. Brasília, Disponível em: https://bit.ly/318knRY. Acesso em: 02 nov. 2018.

BRASIL. Lei no 13.445, de 24 de maio de 2017. Lei da Migração. Brasília, Disponível em: https://bit.ly/2IvBTcp. Acesso em: 02 nov. 2017.

BRASIL. Câmara dos Deputados. Sancionada com vetos nova Lei de Migração. Ministério das Relações Exteriores. Brasília. 2017 b. Disponível em: https://bit.ly/3IOfaqh. Acesso em: 15 jan. 2020.

BRASIL. Ministério das Relações Exteriores. Portal Cosular. Revalidação de diplomas. 2018. Disponível em: https://bit.ly/3dwqBAb. Acesso em: 03 nov. 2018.

BRASIL. Conforme determina a Medida Provisória no 870/2019 a estrutura do Ministério do Trabalho agora integra ao Ministério da Economia. 2019. Disponível em:

https://bit.ly/3dwlMHe. Acesso em: 15 fev. 2020. 
BRASIL. CONSELHO NACIONAL DE IMIGRAÇÃO (CNIG). PROJETO ESTUDO SOBRE A MIGRA ÇÃO HAITIANA AO BRASIL DI ÁlOGO BILATERAL. Brasília. 2014. Disponível em:

https://bit.ly/3k86ISE. Acesso em: 03 nov. 2018.

CANOTILHO, José Joaquim Gomes. Direito Constitucional e Teoria da Constituição. Coimbra: Livraria Almedina, 1997.

CARDOSO, Ruth Corrêa Leite. Estrutura familiar e mobilidade social: estudo dos japoneses no Estado de São Paulo. Org. Paulo Ninomiya. São Paulo: Kaleidos-Primus Consultoria e Comunicação Integrada S/C LTDA, 1998.

CARVALHO, Acelino Rodrigues de. Constituição e Jurisdição: Legitimidade e Tutela dos Direitos Sociais. Curitiba: Juruá, 2015.

COMPARATO, Fábio Konder. A Afirmação Histórica dos Direitos Humanos. 10. ed. São Paulo: Saraiva. 2015.

DALLARI, Dalmo de Abreu. A Constituição na vida os povos: da Idade Média ao Século XXI. São Paulo: Saraiva, 2010.

DESLANDES, Keila; LOURENÇO, Érika (Org.). Por uma cultura dos direitos humanos na escola: princípios, meios e fins. Belo Horizonte: Fino Traço, 2011.

JUNTA COMERCIAL DO ESTADO DE MATO GROSSO DO SUL (JUCEMS) (Mato Grosso do Sul). Agentes Auxiliares - Tradutores. 2020. Disponível em: https://bit.ly/2H4Awkq. Acesso em: 03 mai. 2020.

MARINUCCI, Roberto; MILESI, Rosita. Migrações Internacionais Contemporâneas. Instituto Migrações e Direitos Humanos. Brasília, p. 0-0. 14 jun. 2005. Disponível em: https://bit.ly/2T3BGPz. Acesso em: 03 nov. 2018.

MENEZES, Wagner. Tribunais Internacionais: Jurisdição e Competência. São Paulo: Saraiva, 2013.

MITTLER, Peter. Educação inclusiva. Porto Alegre: Artmed, 2007. Windyz Brazão Ferreira.

OLIVEIRA, Antonio Tadeu Ribeiro de. Nova lei brasileira de migração: avanços, desafios e ameaças. Revista Brasileira de Estudos de População, [s.I.], v. 34, n. 1, p.171-176, 23 ago. 2017. Associacao Brasileira de Estudos Populacionais. http://dx.doi.org/10.20947/s01023098a0010. Disponível em: https://bit.ly/3dwm0hy. Acesso em: 03 nov. 2018.

ONUBR. Texto da Declaração de Incheon disponível em português no site da UNESCO. 2015. Disponível em: https://bit.ly/341dST2. Acesso em: 02 nov. 2018.

PIOVESAN, Flávia. Direitos Humanos e o Direito Constitucional Internacional. $13^{a}$ ed. São Paulo. Saraiva, 2012.

SICILIANO, André Luiz. A política migratória brasileira: limites e desafios. 2013. 67 f. Dissertação (Mestrado) - Curso de Direito, USP, São Paulo, 2013. Disponível em: https://bit.ly/3IPFmB8. Acesso em: 03 nov. 2018.

TARGIONI, Paola. Políticas migratórias, biopolítica e Estado. In: ANPOCS, 41., 2017, Caxambu. GT 16 - Migrações internacionais, Estado, controle e Fronteiras. Minas Gerais: Anpocs, 2017. p. 1 - 19. Disponível em: https://bit.ly/2SUuJk3. Acesso em: 05 dez. 2018.

UNESCO. Declaração Mundial sobre Educação para Todos: satisfação das necessidades básicas de aprendizagem Jomtien, 1990. 1990. Disponível em: https://bit.ly/2H8SiTk. Acesso em: 01 nov. 2018. 
UNESCO. Declaração de Salamanca sobre Princípios, Política e Práticas na Área das

Necessidades Educativas Especiais 1994. Disponível em: https://bit.ly/33YcFvI. Acesso em: 01 nov. 2018.

UNESCO. Educação para todos: compromisso em Dakar. 2000. Disponível em: https://bit.ly/3dy6zW6. Acesso em: 01 nov. 2018.

UNESCO. Declaração de Incheon sobre Assegurar a educação inclusiva e equitativa de qualidade, e promover oportunidades de aprendizagem ao longo da vida para todos. 2015. Disponível em: https://bit.ly/3j2qkWA. Acesso em: 01 nov. 2018.

Recebido em: 7 de junho de 2020. Aceito em: 17 de outubro de 2020. Publicado em: 05 de janeiro de 2021. 